
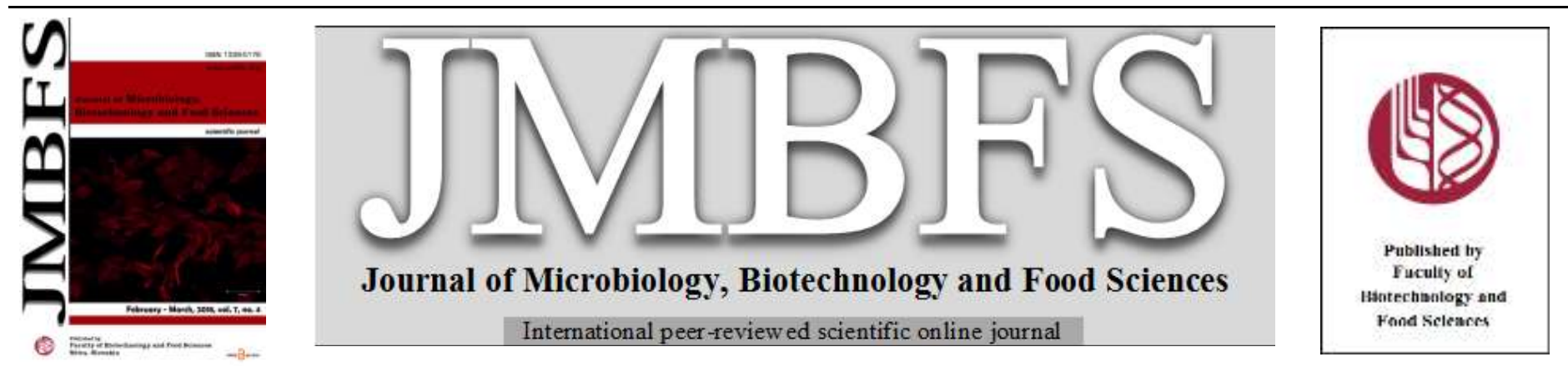

\title{
MALAGASY TRADITIONAL TREATMENTS OF INFECTIOUS PLANT DISEASES EXERT ANTI-VIRULENCE ACTIVITIES AGAINST PSEUDOMONAS AERUGINOSA AND RALSTONIA SOLANACEARUM
}

\author{
Tsiry Rasamiravaka ${ }^{l^{*}}$, Patrick Anthony Raveloson ${ }^{2}$, Rajaonarivelo Philémon Jacob ${ }^{1,2, *}$, Christian Rabemanantsoa ${ }^{2}$, Blandine \\ Andrianarisoa ${ }^{1}$, Pierre Duez ${ }^{3}$, Mondher El Jaziri ${ }^{4}$
}

\author{
Address(es): Rasamiravaka Tsiry, \\ ${ }^{1}$ Laboratory of Biotechnology and Microbiology, Department of Applied and Fundamental Biochemistry, Faculty of Science, University of Antananarivo, (UA), BP \\ 906, Antananarivo 101, Madagascar. \\ ${ }^{2}$ Laboratoire de Microbiologie, Département de Biodiversité, Institut Malgache de Recherches Appliquées (IMRA), BP 3833, Avarabohitra, Antananarivo, Madagascar. \\ ${ }^{3}$ Unit of Therapeutic Chemistry and Pharmacognosy, University of Mons (UMONS), Bât 6, Av. Maistriau, 7000 Mons, Belgium. \\ ${ }^{4}$ Laboratory of Plant Biotechnology (LBV), Free University of Brussels (ULB), CP300, B-6041 Gosselies, Belgium.
}

*Corresponding author: travaka@yahoo.fr

doi: 10.15414/jmbfs.2018.7.4.377-382

\section{ARTICLE INFO}

Received 15. 6. 2017

Revised 9. 11. 2017

Accepted 20. 11. 2017

Published 1. 2. 2018

\section{Regular article}

oren 2 access

\begin{abstract}
Traditional Malagasy farmers have developed a range of biological methods to restrict plant diseases without reliance on external or synthetic inputs. Five common Malagasy traditional practices demonstrated to be efficient against potato crop bacterial disease in experimental fields have been investigated for their antibacterial (i.e. bacteriostatic and bactericidal effects) and anti-virulence (i.e. antiquorum sensing and anti-biofilm) activities against two phytopathogens, Pseudomonas aeruginosa and Ralstonia solanacearum. Results show that polar (methanolic) extracts of recipes exert anti-virulence activities rather than bacteriostatic and/or bactericidal activities. Indeed, three recipes (R5, R7 and R9) reduce the expression of QS-dependent virulence factors whereas only recipe (R5) exhibit antibiofilm activities without affecting bacterial growth. R4 and R6 were not active, suggesting other bacterial targets and/or other bioactivity properties. Innovative approaches, inspired from ancestral practices, should be considered in the struggle against infectious diseases to limit the overuse of antibiotics for controlling infectious plant diseases and to reduce the overspread of multidrug resistant
\end{abstract} bacteria.

Keywords: Biofilm, Quorum sensing, Pseudomonas, Ralstonia

\section{INTRODUCTION}

The current global food needs require agriculture practices to cover large crop surfaces with high output. Plant infectious diseases, factors that reduce productivity, are usually controlled by using chemical products such as pesticides or fungicides and, occasionally, antibiotics (McManus et al., 2002; Stockwell \& Duffy, 2012). The use of such chemical products is controversial, not only for the risk in soil contamination and human intoxication but also for the selection of resistant bacteria strains. In fact, faced with phytopathogenic bacteria, modern agriculture is sorely missing selective antibacterial products with original modes of action that may avoid selective pressure. In a developing country such as Madagascar, traditional farmers have developed a range of methods to restrict plant diseases without reliance on external or synthetic inputs. Although many of their techniques are unknown, poorly understood and documented, they allowed farmers to produce crops with minimal purchased inputs in a difficult tropical environment. Also the active promotion of modern products led to a disaffection towards traditional practices and there is a risk of losing orally transmitted ancestral knowledge. In a recent experimental field study, some Malagasy traditional practices demonstrated curative activity against potato wilt disease due to Ralstonia solanacearum (Rasamiravaka et al., 2017). Effectiveness of these recipes is presumably explained through either bactericidal effects or disruption of phytopathogen development which limits spreading and colonization within plant host. Indeed, the success of an infection relies on the ability of bacteria to survive, colonize, disseminate through their hosts by using different types of motility, form structured biofilms and diffuse virulence factors (Wu et al., 2008).

Relevant phytophatogens that may cause infectious diseases in potato are Ralstonia solanacearum (also called Pseudomonas solanacearum, responsible of wilt disease) and different species of Pseudomonas (responsible of bacterial soft rot) (Mansfield et al., 2012). Additionally, P. aeruginosa is an opportunistic bacterium infecting humans, animals and plants (Arabidopsis thaliana (L.)
Heynh., Nicotiana tabacum L. and Lactuca sativa L.) and is a widely used model for studying anti-virulence properties of natural products (Jimenez et al., 2012; LaSarre \& Federle, 2013). The present study aims to investigate in vitro the five (R4, R5, R6, R7 et R9) common Malagasy traditional practices previously demonstrated to be efficient against potato bacterial disease in experimental fields (Rasamiravaka et al., 2017) by focusing on their possible anti-bacterial and anti-virulence activities against both phytopathogens $R$. solanacearum and $P$. aeruginosa.

\section{MATERIAL AND METHODS}

\section{Recipe preparation and extraction}

In our previous study, 50 practices have been collected from traditional farmers managing rice and potatoes crop (Rasamiravaka et al., 2017). These practices were mainly based on the concoction of plant mixtures with cow dung or manure followed by 2-weeks maceration at room temperature (see Rasamiravaka et al. (2013) for details on collection of material and preparation). Five of these recipes (See Table 1 for composition), shown, in experimental fields, to efficiently treat plants naturally infected with $R$. solanacearum (Figure 1), were selected for the present study. One liter of each recipe was soaked overnight $\left(25^{\circ} \mathrm{C}\right.$, agitation at $50 \mathrm{rpm})$ in methanol $(500 \mathrm{ml})$, filtered on cellulose and concentrated to dryness under vacuum. Extracts were dissolved in DMSO and stored at $-20^{\circ} \mathrm{C}$ until use. Concoctions of plant mixtures with cow dung or manure without maceration or with one-week maceration were also extracted following the same procedure. 
Table 1 Composition of recipes used in this study

\begin{tabular}{|c|c|c|}
\hline $\mathbf{N}^{\circ *}$ & Composition & Quantity (for 20L) \\
\hline \multirow{2}{*}{ R4 } & Cow dung & $1 \mathrm{~kg}$ \\
\hline & Water & sqf \\
\hline \multirow{5}{*}{$\mathbf{R 5}$} & Agave vivipara $\mathrm{L}$. & $1 \mathrm{~kg}$ \\
\hline & Tephrosia purpurea $\mathrm{L}$. & $500 \mathrm{~g}$ \\
\hline & Cow dung & $1 \mathrm{~kg}$ \\
\hline & local soap & $50 \mathrm{~g}$ \\
\hline & Cow dung manure & sqf \\
\hline \multirow{5}{*}{ R6 } & Furcrea foetita (L.) Haw. & $1 \mathrm{~kg}$ \\
\hline & Tephrosia purpurea L. & $500 \mathrm{~g}$ \\
\hline & Cow dung & $1 \mathrm{~kg}$ \\
\hline & local soap & $50 \mathrm{~g}$ \\
\hline & Cow dung manure & sqf \\
\hline \multirow{3}{*}{ R7 } & Melia azedarach $\mathrm{L}$. & $1 \mathrm{~kg}$ \\
\hline & Agave vivipara $\mathrm{L}$. & $1 \mathrm{~kg}$ \\
\hline & Cow dung manure & sqf \\
\hline \multirow{3}{*}{ R9 } & Buddleja madagascariensis Lam & $1 \mathrm{~kg}$ \\
\hline & Agave vivipara $\mathrm{L}$ & $1 \mathrm{~kg}$ \\
\hline & Cow dung manure & sqf \\
\hline
\end{tabular}

\section{Bacterial strains, plasmids and culture conditions}

To determine MIC (Minimal Inhibitory Concentration) and MBC (Minimal Bactericidal Concentration), PAO1 was grown on 24-well micro-plates with $1 \mathrm{~m}$ of LB broth in presence of the methanolic extracts at different concentrations ( 31.25 to $4000 \mu \mathrm{g} / \mathrm{mL}$ ) and incubated at $37^{\circ} \mathrm{C}$ for $24 \mathrm{~h}$. The MIC was defined as the lowest concentration that completely inhibited growth as detected by the naked eye (Chérigo et al., 2009). All inhibited growth culture were then subcultured onto LB agar plate and incubated at $37^{\circ} \mathrm{C}$ for $24 \mathrm{~h}$ to determine the $\mathrm{MBC}$ which was defined as the lowest concentration that yielded negative sub-cultures (Okusa et al., 2007). Gentamicin was used as positive control.

\section{Antibacterial assay}

P. aeruginosa $\mathrm{PAO} 1$ wild-type were grown $\left(37^{\circ} \mathrm{C}\right.$, agitation at $\left.175 \mathrm{rpm}\right)$ in LBMOPS broth $(50 \mathrm{mM}, \mathrm{pH} 7.2)$ supplemented with carbenicillin $(300 \mu \mathrm{g} / \mathrm{mL})$ when required. For the detection of anti-QS activity, two PAO1-derived strains harboring QS-related promoter-lacZ fusions (lasB-lacZ and rhlA-lacZ) and one PAO1-derived strain harboring QS-independent promoter-lacZ fusion (aceAlacZ) were used. Descriptions of the used strains and of the experimental procedure for the determination of QS activity were as previously reported by Rasamiravaka et al. (2013). Ralstonia solanacearum used in this study has been isolated from infected potato plants that present symptoms of bacterial wilt disease (Rasamiravaka et al., 2017). Identification of $R$. solanacearum was confirmed by PCR according to DNA $16 \mathrm{~S}$ amplification protocol (Kutin et al., 2009; Massart et al., 2005).

Biofilm formation and quantification

Biofilm formation was performed on 24-well micro-plates and quantified by crystal violet staining protocol as previously described (Rasamiravaka $\boldsymbol{e t}$ al. 2013). Briefly, an overnight culture of $\mathrm{PAO} 1$ was washed twice and diluted in fresh biofilm broth (BB) medium $\left(\mathrm{Na}_{2} \mathrm{HPO}_{4}, 1.25 \mathrm{~g} / \mathrm{L} ; \mathrm{FeSO}_{4} .7 \mathrm{H}_{2} \mathrm{O}, 0.0005 \mathrm{~g} / \mathrm{L}\right.$ glucose, $0.05 \mathrm{~g} / \mathrm{L} ;\left(\mathrm{NH}_{4}\right)_{2} \mathrm{SO}_{4}, 0.1 \mathrm{~g} / \mathrm{L} ; \mathrm{MgSO}_{4} .7 \mathrm{H}_{2} \mathrm{O}, 0.2 \mathrm{~g} / \mathrm{L}$ and $\mathrm{KH}_{2} \mathrm{PO}_{4}, 0.5$ $\mathrm{g} / \mathrm{L})$. In 24-well polystyrene plates, $50 \mu \mathrm{l}$ of the diluted culture were added to 940 $\mu 1$ of $\mathrm{BB}$ medium (initial $\mathrm{A}_{600}$ of the culture between 0.14 and 0.16 ) and supplemented with $10 \mu \mathrm{l}$ of the tested extract, negative control (DMSO, 1\% final concentration) or positive control (oleanolic acid, $800 \mu \mathrm{M}$ final concentration) (Kiplimo et al., 2011). The methanolic extracts were tested at $100 \mu \mathrm{g} / \mathrm{mL}$ final concentration then, for active extracts at different concentrations (25 to 300 $\mu \mathrm{g} / \mathrm{mL}$ ). PAO1 cultures were incubated statically for 24 hours at $37{ }^{\circ} \mathrm{C}$ and, after staining by crystal violet, the biofilm was quantified at $590 \mathrm{~nm}$ with a SpectraMax M2 device (Molecular Devices).
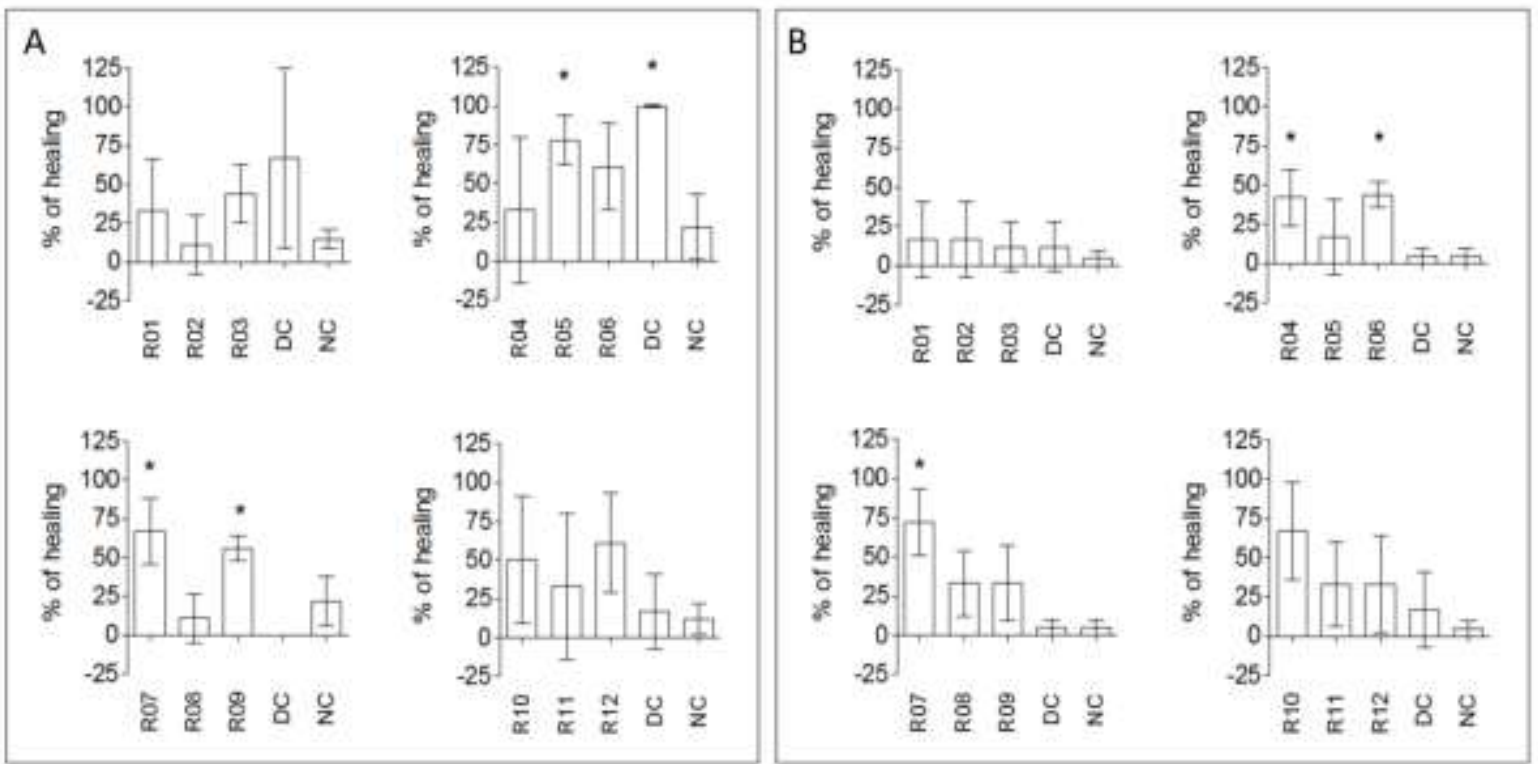

Figure 1 Healing rates observed on experimental parcels of the "Diamondra" (A) and "Meva" (B) potato varieties (Rasamiravaka et al., 2017).

Data were recorded throughout the 14 weeks of the vegetation cycle; 3 independent experiments, each on 4 blocks of 15 plantlets $(n=12)$. Dithane control (DC) represents the positive control. Asterisks indicate data that are statistically different compared to negative control (NC) after Dunnett's multiple comparison tests at $\mathrm{P}<0.01$.

\section{Gene expression and $\beta$-galactosidase measurements}

$\beta$-Galactosidase measurements were performed as previously described (Vandeputte et al., 2010) to monitor gene expression. Briefly, after growth in liquid LB-MOPS-carbenicillin at $37^{\circ} \mathrm{C}$ with agitation $(175 \mathrm{rpm})$ for 18 hours, PAO1 reporter strains were washed twice in fresh LB medium and re-suspended in liquid LB-MOPS-carbenicillin. PAO1 reporter strain inocula $(50 \mu \mathrm{l})$ were incubated $\left(37^{\circ} \mathrm{C}\right.$ with agitation at $\left.175 \mathrm{rpm}\right)$ for 18 hours in $1 \mathrm{ml} \mathrm{LB}-\mathrm{MOPS}$ - carbenicillin (initial $\mathrm{A}_{600}$ of the culture was between 0.020 and 0.025 ) supplemented with either $10 \mu \mathrm{L}$ of methanolic extract dissolved in DMSO (100 $\mu \mathrm{g} / \mathrm{mL}$ final concentration), $10 \mu \mathrm{l}$ DMSO (control condition) or $4 \mathrm{mM}$ of naringenin (Sigma-Aldrich), a compound known as a QS inhibitor in $P$. aeruginosa (positive control) (Vandeputte et al., 2011). After incubation, the bacterial density was assessed by spectrophotometry $\left(\mathrm{A}_{600}\right)$ and the $\beta$ galactosidase was measured with $o$-nitrophenyl- $\beta$-D-galactopyranoside as described by Zhang \& Bremer, (1995). 


\section{Statistics}

All experiments were performed in six replicates and repeated in three independent assays. The data were statistically analyzed by conducting Dunnett's multiple comparison test (i.e. each test was compared with the DMSO-treated cells) and a P-value <0.01 was considered as being significant.

\section{RESULTS}

Bactericide and bacteriostatic activities of five Malagasy traditional practices

Five Malagasy traditional recipes were prepared following traditional users' recommendations and polar (methanolic) extracts were investigated for in vitro antibacterial activities against $R$. solanacearum and $P$. aeruginosa. The positive control, gentamicin, was selected for its reported effectiveness in controlling various bacterial diseases of vegetable crops caused by Pseudomonas and Ralstonia species (Vidaver, 2002). Interestingly, both the MICs and MBCs of the five tested methanolic extract were higher than $4000 \mu \mathrm{g} / \mathrm{mL}$ whereas gentamicinMIC and -MBC were $0.5-2 \mu \mathrm{g} / \mathrm{mL}$ and $1-4 \mu \mathrm{g} / \mathrm{mL}$, against $R$. solanacearum and $P$. aeruginosa, respectively (data not shown). As these recipes seem to not exert bactericidal or bacteriostatic activity against both species, they may exert other biological activities which successfully impair plant infections without killing bacterial population.
Reduction of biofilm formation and QS-dependent virulence factor genes expression in $P$. aeruginosa PAO1

The five Malagasy traditional recipes were assessed for their potential to affect biofilm formation, an important process in plant-bacteria interaction (Bogino et al., 2013). A concentration of $100 \mu \mathrm{g} / \mathrm{mL}$ has been selected according to optimum solvability in DMSO. As shown in Figure 2, anti-biofilm activity is observed in presence of R5 (52 $\pm 5 \%$ inhibition) at $100 \mu \mathrm{g} / \mathrm{mL}$ without affecting bacterial growth in both strains as compared to DMSO control, whereas the other recipes (R4, R6, R7 and R9) did not exert any significant anti-biofilm activities. This anti-biofilm activity appears dose-dependent as no activity is observed at 25 $\mu \mathrm{g} / \mathrm{mL}$ in both strains (Figure 3). Likewise, the five recipes were assessed for their effect on the expression of QS-related virulence factor genes (las $B$ encoding for elastase and rhlA encoding for the precursor of rhamnolipids) in $P$. aeruginosa reporter strains. As shown in Figure 4, R5, R7 and R9 inhibited QS related lasB $(45 \pm 4 \%, 30 \pm 4 \%$ and $32 \pm 3 \%$ of inhibition, respectively as compared to DMSO control) and rhlA (52 $\pm 5 \%, 34 \pm 4 \%$ and $33 \pm 3 \%$ of inhibition, respectively as compared to DMSO control) genes in $P$. aeruginosa PAO1 without affecting the expression of the QS-independent aceA gene (a constitutive gene encoding for isocitrate lyase) (Kretzschmar et al., 2008) whereas R4 and R6 did not inhibit QS-related lasB and rhlA genes at all. These results suggest that the $\mathrm{R} 5, \mathrm{R} 7$ and $\mathrm{R} 9$ recipes affect the ability of both strains to invade and colonize plant host. (a)

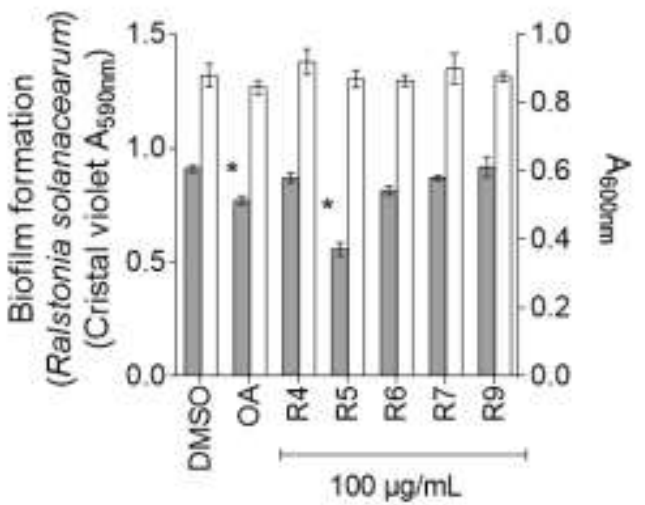

(b)

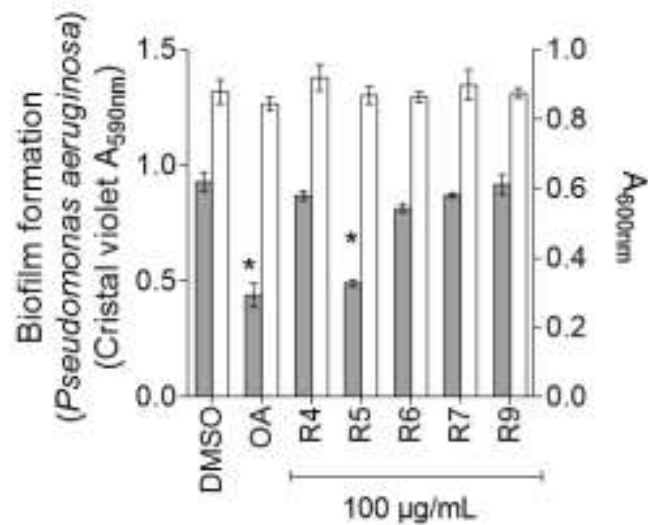

Figure 2 Screening of five recipes extract (R4-R9) on the formation of biofilms (grey bar) and growth turbidity (clear bar) of (a) Ralstonia solanacearum; $\quad$ (b) Pseudomonas aeruginosa $R$. solanacearum and P. aeruginosa PAO1 were grown statically in minimal medium supplemented with DMSO $1 \%$, oleanolic acid $800 \mu \mathrm{M}(\mathrm{OA})$ or methanolic extract after incubation without agitation at $37^{\circ} \mathrm{C}$ for $24 \mathrm{~h}$. The biofilm formation was quantified by crystal violet staining and $\mathrm{A}_{590 \mathrm{~nm}}$ measurement. The cell density of the bacteria was assessed as $\mathrm{A}_{600 \mathrm{~nm}}$. All experiments were performed in triplicate with three independent assays. Error bars represent the standard error of the mean and the asterisks indicate samples that are significantly different from DMSO control (Dunnett's multiple comparison test, $p \leq 0.01$ ).

(a)

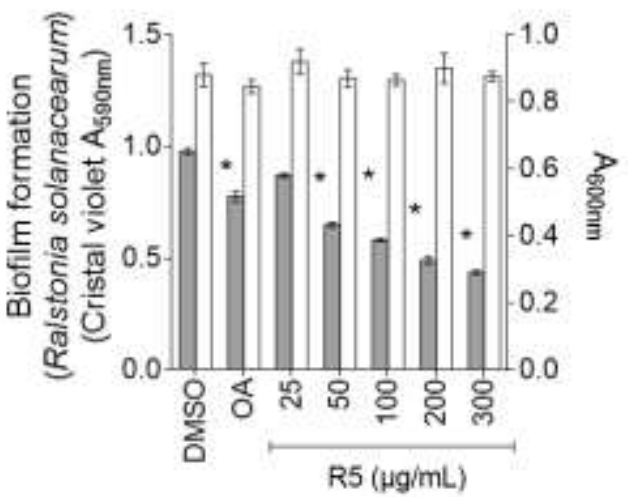

(b)

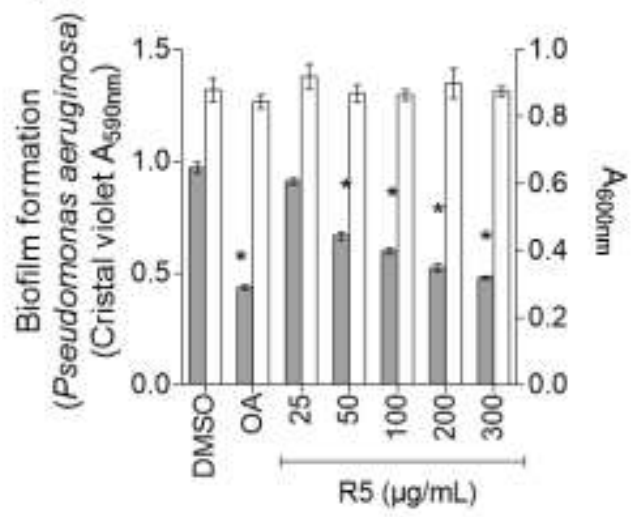

Figure 3 Dose-dependent activity of the R5 recipe on the formation of biofilms (grey bar) and growth turbidity (clear bar) of (a) Ralstonia solanacearum; (b) Pseudomonas aeruginosa PAO1.

$R$. solanacearum and P. aeruginosa PAO1 were grown statically in minimal medium supplemented with DMSO $1 \%$, oleanolic acid $800 \mu \mathrm{M}(\mathrm{OA})$ or different concentrations of R5 (from 50 to $300 \mu \mathrm{g} / \mathrm{mL}$ ) after incubation without agitation at $37^{\circ} \mathrm{C}$ for $24 \mathrm{~h}$. Biofilm formation was quantified by crystal violet staining and measured as $\mathrm{A}_{590 \mathrm{~nm}}$. The cell density of the bacteria was assessed as $\mathrm{A}_{600 \mathrm{~nm}}$. All experiments were performed in triplicate with three independent assays. Error bars represent the standard error of the mean and the asterisks indicate samples that are significantly different from DMSO control condition (Dunnett's multiple comparison test, $p \leq 0.01$ ). 
(a)

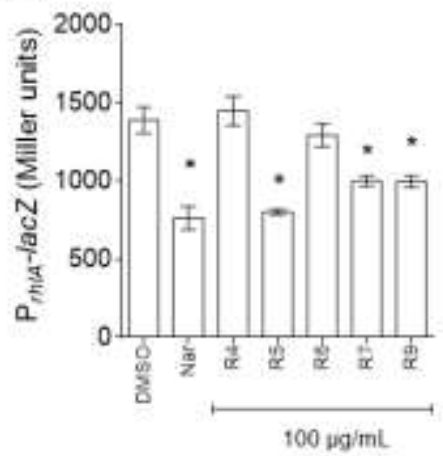

(b)

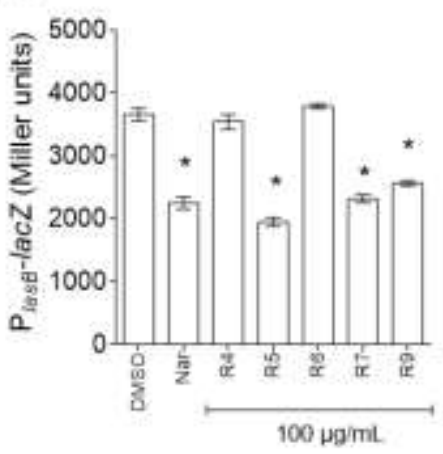

(c)

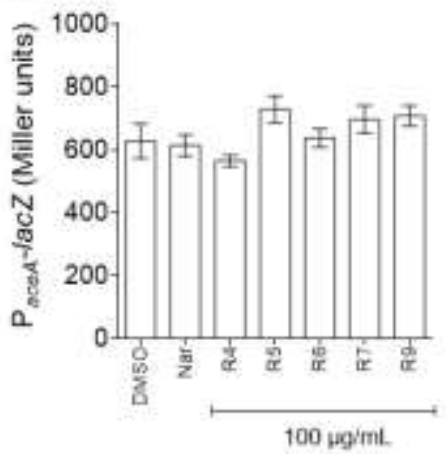

Figure 4. Effect of five recipes extracts on QS-dependent (lasB and rhlA) genes and QS-independent aceA gene expression in $P$. aeruginosa PAO1.

Effect of five recipe extracts at $100 \mu \mathrm{g} / \mathrm{mL}$ on (a) rhlA, (b) lasB and (c) aceA expression following $18 \mathrm{~h}$ of growth. Naringenin (Nar $4 \mathrm{mM}$ ) was used as positive control. Gene expression was measured as the $\beta$-galactosidase activity of the lac $Z$ gene fusions and expressed in Miller units. All experiments were performed in triplicate with three independent assays. Error bars represent the standard errors of the means and asterisks indicate samples that are significantly different from control condition (DMSO) (Dunnett's multiple comparison tests; $p \leq 0.01)$.

\section{Alteration of QS systems in P. aeruginosa PAO1}

Since R5, R7 and R9 reduce the expression of QS-regulated lasB and rhlA genes, we assessed the effect of these 3 recipes on $P$. aeruginosa PAO1 QS systems by measuring the expression of the AHL synthetase genes lasI and rhlI and the QS regulator genes lasR and $r h l R$. As shown in Figure 5, the R5 and R9 extracts significantly reduced $(P<0.01)$ the expression of the AHL synthetase genes rhl (33 $\pm 2 \%$ and $40 \pm 5 \%$ of inhibition, respectively) and lasI $(25 \pm 5 \%$ and $30 \pm 5$ $\%$ of inhibition, respectively). Similarly, R9 significantly reduced the expression of the QS regulator genes $\operatorname{rhlR}(29 \pm 3 \%$ of inhibition) and lasR gene (19 $\pm 3 \%$ of inhibition). The R7 extract does not exert any inhibition on the expression of the las and $r h l$ genes. These results demonstrate that the three recipes impaired differently the QS system, suggesting different targets in QS system modulation.

(a)

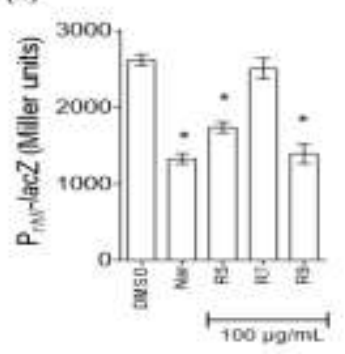

(c)

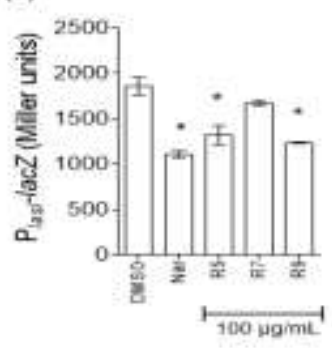

(b)

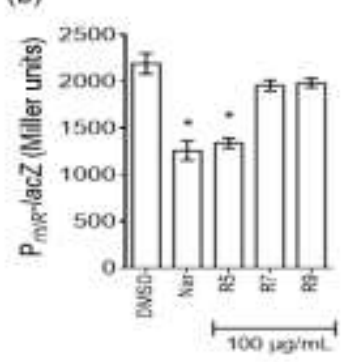

(d)

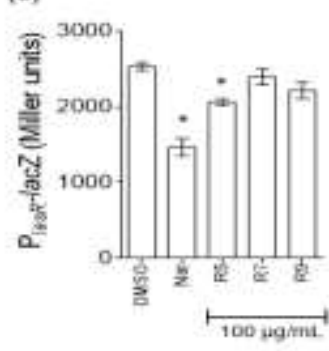

Figure 5 Effect of R5, R7 and R9 extracts on Pseudomonas aeruginosa quorum sensing (QS) regulator genes (a: lasI; b: lasR; c: rhll; d: rhlR). The R5, R7 and R9 extracts were tested at $100 \mu \mathrm{g} / \mathrm{mL}$. DMSO (1\% [vol/vol], final concentration) was used as solvent control and naringenin (Nar: $4 \mathrm{mM}$, final concentration) as QS inhibitory control. *Significance at $P<0.01$. All experiments were performed in six biological replicates.

\section{Influence of recipes preparation on bioactivity}

The preparation of recipes is based on the concoction of plant mixture with cow dung or manure followed by 2 weeks maceration at room temperature. As frequently suggested by interviewed traditional users (Rasamiravaka $\boldsymbol{e t}$ al., 2017), the duration of recipe maceration would be a quite important factor. Therefore, we assessed the anti-QS effects of effective recipes R5, R7 and R9 extracted after 3 distinct maceration durations: $(i)$ at the date of mixing herbs and dung, which means no maceration; (ii) at 7 th day of maceration; and (iii) at $14^{\text {th }}$ day of maceration. All extracts were tested at $100 \mu \mathrm{g} / \mathrm{mL}$ final concentration. As shown in Figure 6, the 3 recipes extracted at the beginning of maceration do not reduce las $B$ and $r h l A$ gene expression. However, the R5 and R7 extracted at 7th day after maceration reduce the expression of genes $\operatorname{las} B(30 \pm 5 \%$ and $25 \pm 3 \%$ of inhibition, respectively) and rhlA (33 $\pm 5 \%$ and $30 \pm 4 \%$ of inhibition, respectively) contrarily to $\mathrm{R} 9$ which is not active. Finally, the expression of genes las $B$ and $r h l A$ gene is reduced by the three recipes extracted at $14^{\text {th }}$ day of maceration, similarly to inhibitions recorded in Figure 4. Regarding the antibiofilm effects of recipes R5 against $R$. solanacearum and $P$. aeruginosa, only the recipe R5 extracted at $14^{\text {th }}$ day of maceration is effective $(30 \pm 5 \%$ and $25 \pm$ $3 \%$ of inhibition, respectively; Figure 7). These results suggest a biotransformation process that generates active compounds inside recipe mixture. Moreover, the generation of anti-biofilm activity (Figure 7) needs more maceration time compared to anti-QS activities (Figure 5) suggesting a more complex biosynthesis pathway of active compound(s). 
(a)

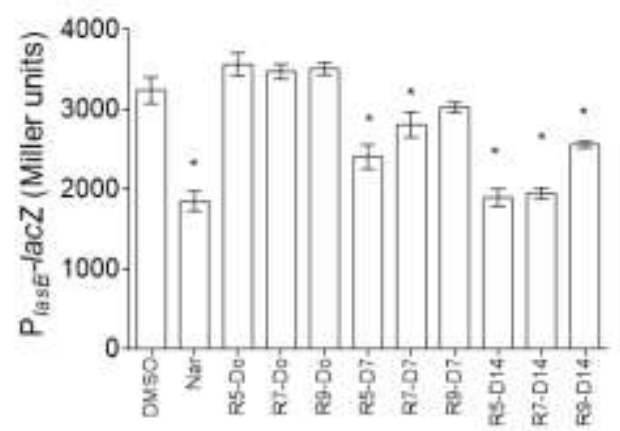

(b)

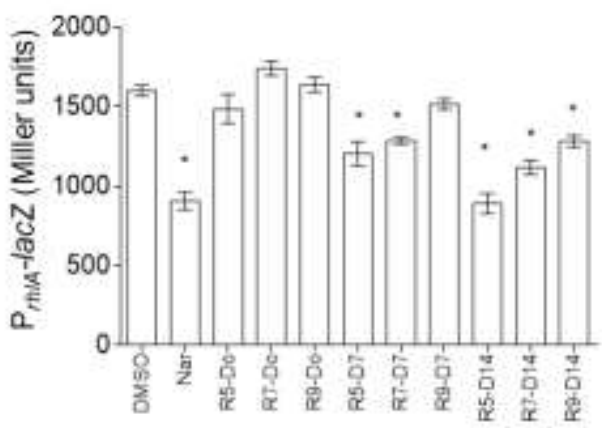

Figure 6. Effect of R5, R7 and R9 recipes with different times of maceration (D0, D7 and D14 of maceration) on the expression of QS-dependent (lasB and rhlA) genes in P. aeruginosa PAO1.

Effect of R5, R7 and R9 extracts on (a) lasB and (b) rhlA expression following $18 \mathrm{~h}$ of growth. Naringenin (Nar 4mM) was used as positive control. The gene expression was measured as the $\beta$-galactosidase activity of the lac $Z$ gene fusions and expressed in Miller units. All experiments were performed in triplicate with three independent assays. Error bars represent the standard errors of the means and asterisks indicate samples that are significantly different from control condition (DMSO) (Dunnett's multiple comparison test; $p \leq$ $0.01)$.

(a)

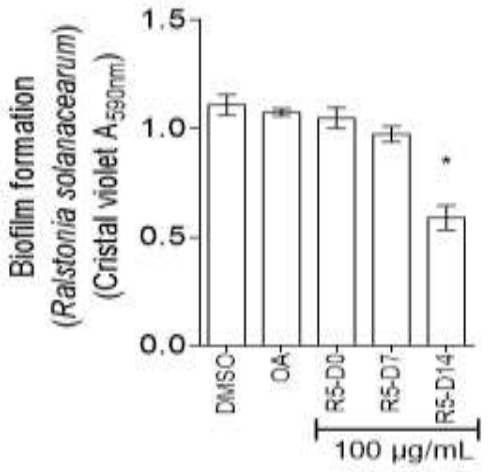

(b)

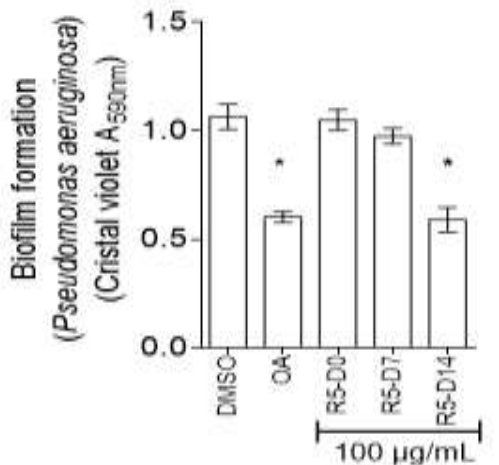

Figure 7. Biofilm formation in the presence of the R5 extract with different durations of maceration (D0, D7 and D14 of maceration). (a) Effect of R5 recipe on biofilm formation of Ralstonia solanacearum. (b) Effect of R5 recipe on biofilm formation of $P$. aeruginosa PAO1. R. solanacearum and $P$. aeruginosa PAO1 were grown in minimal medium supplemented with DMSO $1 \%$, oleanolic acid 800 $\mu \mathrm{M}(\mathrm{OA})$ or R5 recipes (extracted at D0, D7 and D14) after incubation without agitation at $37^{\circ} \mathrm{C}$ for $24 \mathrm{~h}$. The biofilm formation was quantified by crystal violet staining and $\mathrm{A}_{590 \mathrm{~nm}}$ measurement. The cell density of the bacteria was assessed as $\mathrm{A}_{600 \mathrm{~nm}}$. All experiments were performed in triplicate with three independent assays. Error bars represent the standard error of the mean and the asterisks indicate samples that are significantly different from DMSO control (Dunnett's multiple comparison test, $p \leq 0.01$ ).

\section{DISCUSSION}

This study is the first in vitro investigation of the antimicrobial activities of Malagasy traditional crop treatments which highlights that polar extracts of these recipes exert anti-virulence rather than anti-bactericidal activities. Indeed, R5 inhibits biofilm formation in both strains and inhibits QS system in $P$. aeruginosa whereas R7 and R9 exert only anti-QS activities. Interestingly, QS inhibition phenotypes (Figure 4 ) in the 3 recipes are significantly different, suggesting the presence of either different active compound or similar compounds in different proportions. Although R4 and R6 were not active, they may contain active compounds which do not target the tested strains. Indeed, other bacteria species can be responsible of soft rot such as Pectobacterium spp. (MarquezVillavicencio et al., 2011), arguing that investigation should be extended to other phytopathogens. Likewise, $R$. solanacearum reporter strains should be generated to comprehend if active recipe would also affect virulence factors expression and quorum sensing mechanisms in $R$. solanacearum as it does for $P$. aeruginosa Regarding the importance of maceration time, one hypothesis is that observed activities are the result of compounds newly generated during maceration period through a biotransformation process. Such biotransformation is possible as one of the major components of recipe is dung considered as a "complex bacterial mixture" that can presumably generate secondary metabolites during bacterial growth. One can assume that components of recipes do not contain the bioactive compound(s) in significant levels at the beginning of the maceration process. Moreover, the components of each recipe did not exert any anti-QS nor antibiofilm activity when tested individually (data not shown). The challenge will be to isolate bioactive compound(s) and to identify the role of each recipe's component (Table 1) in this putative biotransformation process. One relevant point is to clarify in which way all components are necessarily needed to generate bioactivity. This point is important to optimize and standardize the use of such recipes in the struggle against plant bacterial infection. In that, one difficulty is the presence of dung that represents a highly complex bacterial mixture, its composition being highly dependent on the food composition of local cows.

\section{CONCLUSION}

The present study reports anti-virulence properties of traditional practices used to treat infectious plant diseases. This approach may be considered as an alternative approach compared to the use of expensive modern treatments, often ineffective on bacterial infections.

Innovative approaches, inspired from ancestral practices, should be considered in the struggle against infectious diseases to limit the overuse of antibiotics for controlling infectious plant diseases and to reduce the overspread of multidrug resistant bacteria. Combining the best of traditional agriculture methods with the best of modern agriculture should go a long way towards sustaining agriculture in the coming decennia.

Conflict of interest: The author confirms that this article content has no conflict of interest

Acknowledgments: This research was supported by the project PIC-Madagascar 2009 of the ARES-CCD (Académie de Recherche et d'Enseignement SupérieurCommission Coopération au Développement, Belgium) through the postdoctoral 
fellowship "ELAN 2015-2016" and by David and Alice Van Buuren foundation, Université Libre de Bruxelles. We would like to thank Professor Junichi Kato, Hiroshima University (Department of Molecular Biotechnology), Japan, for kindly providing plasmids p $\beta 01$, p $\beta 02$; Professor Helmut Görisch, Technische Universität Berlin (Fachgebiet Technische Biochemie, Institut für Biotechnologie), Germany, for providing plasmid pTB4124; Mrs L. M. Razanakoto and Prof. H. Jijakli (Gembloux Agro-Bio Tech, University of Liège, Belgium) for providing the $R$. solanacearum strain.

\section{REFERENCES}

Bogino, P. C., Oliva, M. D. L. M., Sorroche, F. G., \& Giordano, W. (2013). The role of bacterial biofilms and surface components in plant-bacterial associations. International Journal of Molecular Sciences, 14(8), 15838-15859. https://doi.org/10.3390/ijms140815838

Chérigo, L., Pereda-Miranda, R., \& Gibbons S. (2009). Bacterial resistance modifying tetrasaccharide agents from Ipomoea murucoides. Phytochemistry, 70(2), 222-227. http://dx.doi.org/10.1016/i.phytochem.2008.12.005

Jimenez, P. N., Koch, G., Thompson, J. A., Xavier, K. B., Cool, R. H. \& Quax W. J. (2012). The multiple signaling systems regulating virulence in Pseudomonas aeruginosa. Microbioly and Molecular Biology Review, 76, 46-65. https://doi.org/10.1128/MMBR.05007-11

Kiplimo, J.J., Koorbanally, N.A., Chenia, H. (2011). Triterpenoids from Vernonia auriculifera Hiern exhibit

antimicrobial activity. African Journal of Pharmacy and Pharmacology, 5, 1150 1156. https://doi.org/10.5897/AJPP11.183

Kretzschmar, U., Khodaverdi, V., Jeoung, J.H., \& Görisch, H. (2008). Function and transcriptional regulation of the isocitrate lyase in Pseudomonas aeruginosa. Archives of Microbiology, 190, 151-158. https://doi.org/10.1007/s00203-0080381-7

Kutin, R. K., Alvarez A., Jenkins, D.M. (2009). Detection of Ralstonia solanacearum in natural substrates using phage amplification integrated with real-time PCR assay. Journal of Microbiological Methods, 76, 241-246. https://doi.org/10.1016/j.mimet.2008.11.008

Lasarre, B., \& Federle, M. J. (2013). Exploiting quorum sensing to confuse bacterial pathogens. Microbiology and Molecular Biology Reviews, 77(1), 73111. https://doi.org/10.1128/MMBR.00046-12

Mansfield, J., Genin, S., Magori, S., Citovsky, V., Sriariyanum, M., Ronald, P. Dow, M., Verdier, V., Beer, S.V., Machado, M.A., Toth, I., Salmond, G., Foster, G.D. (2012). Top 10 plant pathogenic bacteria in molecular plant pathology. Molecular Plant Pathology, 13(6), 614-629. https://doi.org/10.1111/j.13643703.2012.00804.x

Marquez-Villavicencio, M.D.P., Groves, R.L., \& Charkowski. A.O. (2011). Sof rot disease severity is affected by potato physiology and Pectobacterium taxa. Plant Disease, 95, 232-241. https://doi.org/10.1094/PDIS-07-10-0526

Massart, S. De Clercq, D., Salmon, M., Dickburt, C., Jijakli, M. J (2005) Development of real-time PCR using Minor Groove Binding probe to monitor the biological control agent Candida oleophila (strain O). Journal of Microbiological Methods $\quad 60, \quad 73-82$. http://dx.doi.org/10.1016/j.mimet.2004.08.012

McManus, P.S., Stockwell, V.O., Sundin, G.W. \& Jones, A.L. (2002). Antibiotic use in plant agriculture. Annual Review of Phytopathology, 40, 443-465. https://doi.org/10.1146/annurev.phyto.40.120301.093927

Okusa, P. N., Penge, O., Devleeschouwer, M., \& Duez, P. (2007). Direct and indirect antimicrobial effects and antioxidant activity of Cordia gilletii De Wild (Boraginaceae). Journal of ethnopharmacology, 112(3), 476-481. https://doi.org/10.1016/i.jep.2007.04.003

Rasamiravaka, T., Rajaonarivelo, J. P., Rabemanantsoa, C., El Jaziri, M., Andrianarisoa, B., \& Duez, P. (2017). Malagasy traditional treatments for food crops: A tool to control potato bacterial diseases?. Crop Protection, 102, 49-55. https://doi.org/10.1016/j.cropro.2017.08.011

Rasamiravaka, T., Jedrzejowski, A., Kiendrebeogo, M., Rajaonson, S. Randriamampionona, D., Rabemanantsoa, C., Andriantsimahavandy, A., Rasamindrakotroka. A., El Jaziri, M., \& Vandeputte, O. M. (2013). Endemic Malagasy Dalbergia species inhibit quorum sensing in Pseudomonas aeruginosa PAO1. Microbiology, 159(5), 924-938. https://doi.org/10.1099/mic.0.064378-0

Stockwell, V. O., \& Duffy, B. (2012). Use of antibiotics in plant agriculture Scientific and Technical Review (International Office of Epizootics), 31(1), 199 210. https://doi.org/10.20506/rst.31.1.2104

Vandeputte, O. M., Kiendrebeogo, M., Rasamiravaka, T., Stévigny, C., Duez, P. Rajaonson, S., Diallo, B., Mol, A., Baucher, M., \& El Jaziri, M. (2011). The flavanone naringenin reduces the production of quorum sensing-controlled virulence factors in Pseudomonas aeruginosa PAO1. Microbiology, 157, 21202132. https://doi.org/10.1099/mic.0.049338-0

Vidaver, A.K. (2002). Uses of antimicrobials in plant agriculture. Clinical infectious Diseases, 34, S107-110. https://doi.org/10.1086/340247

Wu, H.-J., Wang, A. H. J., \& Jennings, M. P. (2008). Discovery of virulence factors of pathogenic bacteria. Current Opinion in Chemical Biology 12, 93-101. https://doi.org/10.1016/j.cbpa.2008.01.023
Zhang, X., \& Bremer, H. (1995). Control of the Escherichia coli rrnB P1 promoter strength by ppGpp. Journal of Biological Chemistry, 270, 1118111189. https://doi.org/10.1074/jbc.270.19.11181 